\title{
Anchusa italica Retz. Hydro-Alcoholic Extract through Attenuation of Oxidative Stress Exerts an Anticonvulsant Effect on the Pentylenetetrazole-Induced Seizure in Mice
}

\author{
Mohammad Rahimi-Madiseh ${ }^{1, *}$ Shakiba Nasiri-Boroujeni ${ }^{1, *}$ Zahra Lorigooini ${ }^{1}$ Meysam Nazari ${ }^{1}$ \\ Reihaneh Sadeghian ${ }^{1}$ Mahmoud Rafieian-Kopaei ${ }^{1}$ Hossein Amini-Khoei ${ }^{1 \odot}$ \\ ${ }^{1}$ Medical Plants Research Center, Basic Health Sciences Institute, \\ Shahrekord University of Medical Sciences, Shahrekord, Iran \\ Int J Ep 2021;7:52-58. \\ Address for correspondence Hossein Amini-Khoei, PhD, Medical \\ Plants Research Center, Basic Health Sciences Institute, Shahrekord \\ University of Medical Sciences, Shahrekord 12345782, Iran \\ (e-mail: aminikhoyi@gmail.com; aminikhoyi.h@skums.ac.ir).
}

\section{Introduction}

Epilepsy is one of the most common chronic neurological disorders that affect $\sim 1 \%$ of the world population. ${ }^{1,2}$ Varied range of etiologies such as central nervous system infections,

\footnotetext{
These are the co-first authors.
}

Introduction It has been shown that oxidative stress is involved in the pathophysiology of seizure. Current anticonvulsants have side effects, thus further studies are needed to find new agents with low side effects. Anchusa italica Retz. has been suggested to have antioxidant and neuroprotective effects. The present study aimed to determine the anticonvulsant effects of $A$. italica hydro-alcoholic extract on pentylenetetrazole (PTZ)-induced seizures in mice focusing on its possible antioxidative stress properties.

Materials and Methods Sixty mice were randomly divided into six groups. The intervention groups received the $A$. italica extract at the doses of 50, 100, and $200 \mathrm{mg} / \mathrm{kg}$, 30 minutes before the injection of PTZ, whereas the positive control group received phenobarbital. The seizure threshold was then recorded.

Results $A$. italica extract significantly increased the seizure threshold. The extract significantly increased serum and prefrontal cortex total antioxidant capacity compared with the control group. The $A$. italica extract significantly reduced serum and prefrontal cortex malondialdehyde and nitrite levels compared with the control group. Conclusions The results showed the anticonvulsant effects of $A$. italica extracts on the PTZ-induced seizure in mice is partially due to the attenuation of oxidative stress. published online

February 18, 2022
DOI https://doi.org/ $10.1055 / \mathrm{s}-0041-1742275$. ISSN 2213-6320. brain injuries, brain tumors, and cerebrovascular disorders is involved in the development of seizure. ${ }^{3}$ While the causes of seizures are widely classified, the full mechanisms involved in the disease are not fully understood. Commonly prescribed drugs are associated with various side effects, and, in addition, some patients are resistant to these drugs. ${ }^{4,5}$

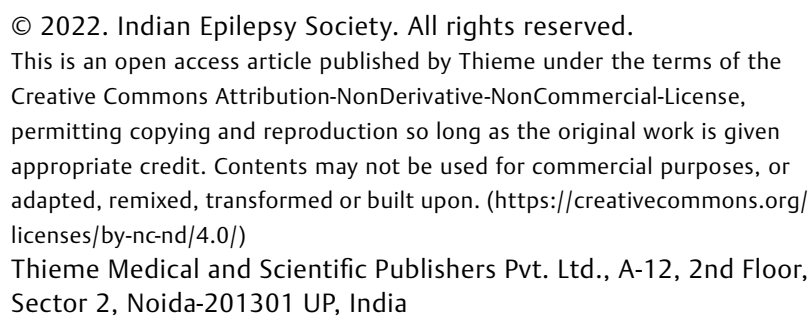


Therefore, the introduction of new drugs with fewer side effects and more effectiveness is strongly felt.

Nitric oxide (NO) plays a key role in various pathophysiological and physiological processes in the nervous system and its related disorders. ${ }^{6,7}$ Recently, NO has been shown to be involved in stimulating and exacerbating seizures in rodents. ${ }^{8}$ Researchers have shown that the increased levels of NO is associated with decrease in seizure threshold in the pentylenetetrazole (PTZ) model of seizure in rodents. ${ }^{9}$

Besides, several experimental models of seizures have demonstrated an increase in the oxidative stress markers, such as malondialdehyde (MDA), as the end-product of lipid peroxidation, in the brain. ${ }^{10}$ High oxidative stress state and free radical generation are possible causes of seizure-induced neuronal apoptosis and death. ${ }^{11}$ Previously, it has been determined that seizures are associated with decrease in total antioxidant capacity (TAC) in the brain and serum samples. ${ }^{12,13}$ Therefore, agents that can reduce the level of oxidative stress markers and increase antioxidant capacity may potentially have anticonvulsant effects.

Using plant- or herbal-derived compounds for treatment of diseases has currently been specially considered. Hence, researchers are trying to introduce herbal medicines for management of diseases. ${ }^{14}$ Medicinal plants have long attracted much attention and have been used extensively in traditional medicine. Today, the effects of a large number of these plants in seizures have been studied and their anticonvulsant effects have been confirmed. ${ }^{14-16}$ Recent studies showed that consumption of medicinal plant or natural products as antioxidants is an approach for management of neurological diseases. Anchusa italica Retz. belongs to the Boraginaceae family, mostly found in temperate regions, especially in the Mediterranean and tropical regions. A. italica Retz. has many pharmacological properties, including anticancer, antiviral, cardioprotective, and antioxidants effects. ${ }^{17,18}$

Considering all the information mentioned above, in the current study, using PTZ, a seizure-provoking agent in rodents, anticonvulsant effects of hydro-alcoholic extract of the A. italica was investigated, focusing on its possible antioxidative stress properties.

\section{Materials and Methods}

\section{Plant Material and Preparation of Hydro-Alcoholic Extract of $\boldsymbol{A}$. italica}

The plant was collected from the margins of Saman city in Chaharmahal va Bakhtiari province. A. italica flowers were gathered and botanically confirmed by a botanist (Shirmardi, Hamzeh Ali, PhD, Research Center of Agriculture and Natural Resources, P.O. Box 415, Shahrekord, Iran) and deposited as specimens in Herbarium of Medical Plants Research Center in Shahrekord University of Medical Sciences, Shahrekord, Iran (SKUMS-504). In the next step, by maceration method, $1,000 \mathrm{~g}$ of it was macerated in $3,000 \mathrm{~mL}$ of $70 \%$ ethanol and kept on a shaker at room temperature for 48 hours. The resulting mixture was filtered and the solvent was evaporated by a rotary evaporator at $38^{\circ} \mathrm{C}$. The extract was completely dried in the incubator under $40^{\circ} \mathrm{C}$.

\section{Standardization of Extract}

The total phenolic content of A. italica extract was calculated using Folin-Ciocalteu method. To this end, $1 \mathrm{mg} / \mathrm{mL}$ extract achieved a volume of $3 \mathrm{~mL}$ by adding up distilled water and then mixed with $0.5 \mathrm{~mL}$ Folin-Ciocalteu reagent for 10 minutes. After that, $4 \mathrm{~mL}$ of sodium carbonate was added to the consequential mixture. The obtained mixture was kept in the dark for half an hour and the optical absorbance was read at $765 \mathrm{~nm}$ wavelength. The experiments were conducted in triplicate. The total phenolic content was measured by using a calibration curve, and the results were expressed as $\mathrm{mg}$ of Gallic acid equivalent/g dried extract. ${ }^{19}$

\section{Ethical Approval}

The present study was conducted following the guidelines for the care and use of laboratory animals as adopted by the committee on the care and use of laboratory animals of the Shahrekord University of Medical Science (IR.SKUMS. REC.1396.103).

\section{Experimental Animals}

The male NMRI mice, weighing 25 to $30 \mathrm{~g}$, were used in the present study. Animals were kept under standard laboratory conditions, including $24^{\circ} \mathrm{C}$ temperature and a 12-hour darkness cycle with free access to water and food. They were randomly divided into six groups $(n=10)$. Animals in group 1 (positive control) received phenobarbital at a dose of $4 \mathrm{mg} / \mathrm{kg}$ (i.p.) as a standard antiseizure drug, whereas those in group 2 (negative control group) received normal saline at a dose of $90 \mathrm{mg} / \mathrm{kg}$ (i.p.). Animals in groups 3, 4, and 5 (therapeutic groups) received $A$. italica extract at the doses of 50,100 , and $200 \mathrm{mg} / \mathrm{kg}$ (i.p.). All agents in groups 1 to 5 were administrated 30 minutes before PTZ (i.v.). Animals in group 6 were healthy controls who received normal saline (i.p.) without PTZ. The dose and time of administrations were chosen based on our pilot study.

\section{Evaluation of Seizure Threshold}

To induce a seizure, PTZ $(10 \mathrm{mg} / \mathrm{mL})$ was infused into the tail vein of freely moving mice at a constant rate $(0.3 \mathrm{~mL} / \mathrm{min})$ using a 30-gauge needle. After fixing the mice's tail, the PTZ was injected by a seizure pump. The injection was stopped as soon as the clonus of the anterior limb was seen. The minimum dose of PTZ for the seizure was considered as the dose of seizure threshold. In this method, the seizure threshold was dependent on the PTZ dose and time. ${ }^{20}$

\section{Measuring Serum and Prefrontal Cortex Antioxidant Capacity}

In the next step, the animals were sacrificed, and their prefrontal cortex and serum were isolated and transferred for biochemical measurements of the tissue or serum. Three solutions were used to measure the antioxidant capacity of samples 
including solution 1 (1.55 mL of sodium acetate, $8 \mathrm{~mL}$ of acetic acid, and $500 \mathrm{~mL}$ of distilled water), solution 2 (270 mg iron chloride, which dissolved in $250 \mathrm{~mL}$ of distilled water), and solution 3 (prepared by dissolving of $47 \mathrm{mg}$ treeazin in $40 \mathrm{~mL}$ of hydrochloric acid [ $40 \mathrm{mM}]$ ). The work-up solution was prepared from $10 \mathrm{~mL}$ of solution $1,1 \mathrm{~mL}$ of solution 2 , and $1 \mathrm{~mL}$ of solution 3. Also, $25 \mu \mathrm{L}$ of the serum or homogeneous prefrontal cortex samples was added to $1.5 \mathrm{~mL}$ of the work-up solution and placed at $37^{\circ} \mathrm{C}$ for 10 minutes, and then the optical absorption at the wavelength of $593 \mathrm{~nm}$ was recorded. ${ }^{21}$

\section{Measurement of Serum Malondialdehyde}

In summary, $0.5 \mathrm{~g}$ of thiobarbituric acid was mixed with $80 \mathrm{~mL}$ of acetic acid (20\%), adjusted to $\mathrm{pH} 5 / 3$ by sodium hydroxide, and the volume was diluted with $20 \%$ acetic acid per $100 \mathrm{~mL}$. Next, $100 \mu \mathrm{L}$ of the serum sample was mixed with $100 \mu \mathrm{L}$ of sodium dodecyl sulfate solution (1.8\%) and $2.5 \mathrm{~mL}$ of the workup solution. The samples were placed in boiling water for 1 hour, then cooled and centrifuged at 4,000 rpm. The optical absorbance of the supernatant was recorded at $523 \mathrm{~nm}^{22}$

\section{Measurement of Prefrontal Cortex Malondialdehyde}

One gram of the prefrontal cortex tissue was homogenized in $2.5 \%$ potassium chloride (10\%) and incubated at $37^{\circ} \mathrm{C} \pm 1$ in a metabolic shaker for 60 minutes. After 1 hour of incubation, $1 \mathrm{~mL}$ of trichloroacetic acid (5\%) plus $1 \mathrm{~mL}$ of $67 \%$ thiobarbituric acid was added and mixed well after each stage. The combination of each vial was transferred to a centrifuge tube and centrifuged at 2,000 g for 15 minutes. Afterwards, the supernatant was transferred to another tube and placed in a boiling water bath. Ten minutes later, the test tubes were cooled and the absorbance of each portion was measured at $535 \mathrm{~nm} .^{22}$

\section{The Nitrite Assay}

The Griess reaction was adapted to measure nitrite as depicted. Briefly, the standard curves for nitrite were prepared, and the samples ( $50 \mu \mathrm{L}$ of serum and $100 \mu \mathrm{L}$ of tissue suspensions) were added to the Griess reagent. Proteins were precipitated by adding $50 \mu \mathrm{L}$ of $10 \%$ trichloroacetic acid (Sigma-Aldrich). The contents were centrifuged, and the supernatants were transferred to a 96-well flat-bottomed microplate. Absorbance was read at $520 \mathrm{~nm}$ using a microplate reader, and the final values were calculated from the standard calibration plots. ${ }^{23}$

\section{Statistical Analysis}

Statistical analysis was performed using SPSS18 software. One-way analysis of variance followed by Tukey's post-hoc test was used for data analysis. Values are expressed as mean \pm standard error, and $p<0.05$ was considered statistically significant.

\section{Results}

\section{Standardization of Extract}

Based on Folin-Ciocalteu method, the total phenol content of A. italica extract was determined: $72.2 \pm 0.6 \mathrm{mg}$ of Gallic acid equivalent/g of the dried extract.

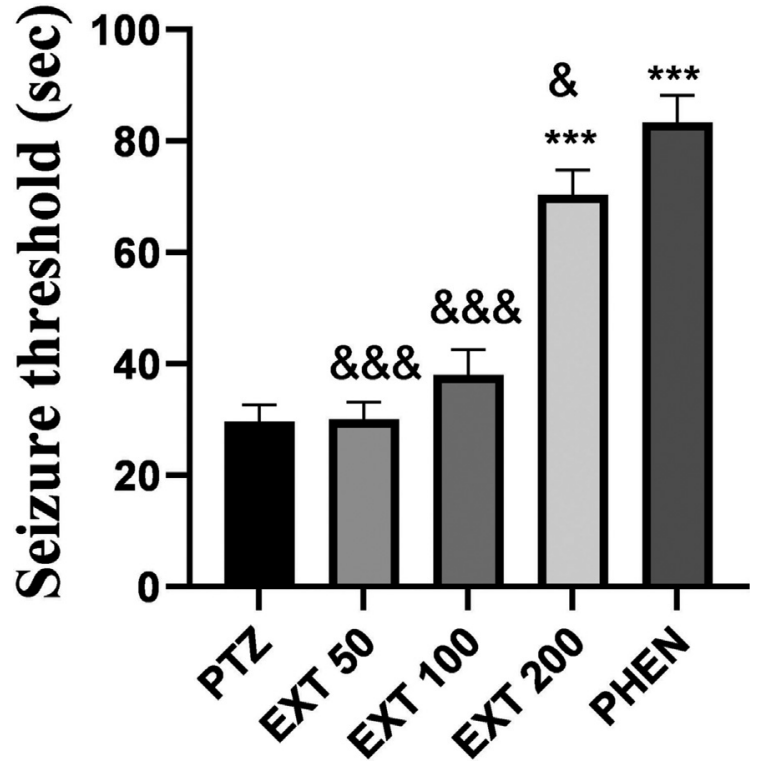

Fig. 1 The seizure threshold (seconds) in the experimental groups. Data are presented as mean \pm standard error from 10 mice and were analyzed using one-way analysis of variance followed by Tukey's post-hoc test.

${ }^{* * *} p<0.001$ compared with the PTZ group, $\& p<0.05$, and $\& \& \& p<0.001$ compared with the PHEN group. EXT, Anchusa italica Retz. hydro-alcoholic extract; PHEN, phenobarbital; PTZ, pentylenetetrazole.

\section{Seizure Threshold}

The results of the mean delay in the onset of seizure (seizure threshold) are presented in -Fig. 1. Findings showed that the mean delay significantly increased in the extract-treated group ( $200 \mathrm{mg} / \mathrm{kg} ; p=0.0007)$ as well as phenobarbital group ( $p=0.0003$ ), compared with the PTZ group. Furthermore, results showed that seizure threshold in the group that received phenobarbital was significantly higher than groups treated with extract at doses of $50(p=0.0002), 100$ $(p=0.0005)$, and $200 \mathrm{mg} / \mathrm{kg}(p=0.0397)$.

\section{Serum Total Antioxidant Capacity}

-Fig. 2 indicates that the TAC in the PTZ group significantly decreased, compared with the control group $(p=0.0452)$. We observed that all three doses of extract significantly increased the TAC in comparison with the PTZ group $(p=0.0004)$. Furthermore, results showed that serum TAC in groups treated with extract at doses of $50(p=0.0003), 100$ $(p=0.004)$, and $200 \mathrm{mg} / \mathrm{kg}(p=0.0006)$ was significantly higher than the group receiving phenobarbital.

\section{Serum Malondialdehyde (MDA) Level}

According to - Fig. 3, serum MDA level in the PTZ group is significantly higher than in the control group $(p=0.008)$. Also, A. italica extract at doses of 50,100 , and $200 \mathrm{mg} / \mathrm{kg}$ as well as phenobarbital significantly reduced MDA in the serum samples in comparison with the PTZ group $(p=0.0007)$. In addition, finding showed that serum MDA level in group treated with extract at dose of $50 \mathrm{mg} / \mathrm{kg}$ was significantly higher than group receiving phenobarbital $(p=0.0216)$. 


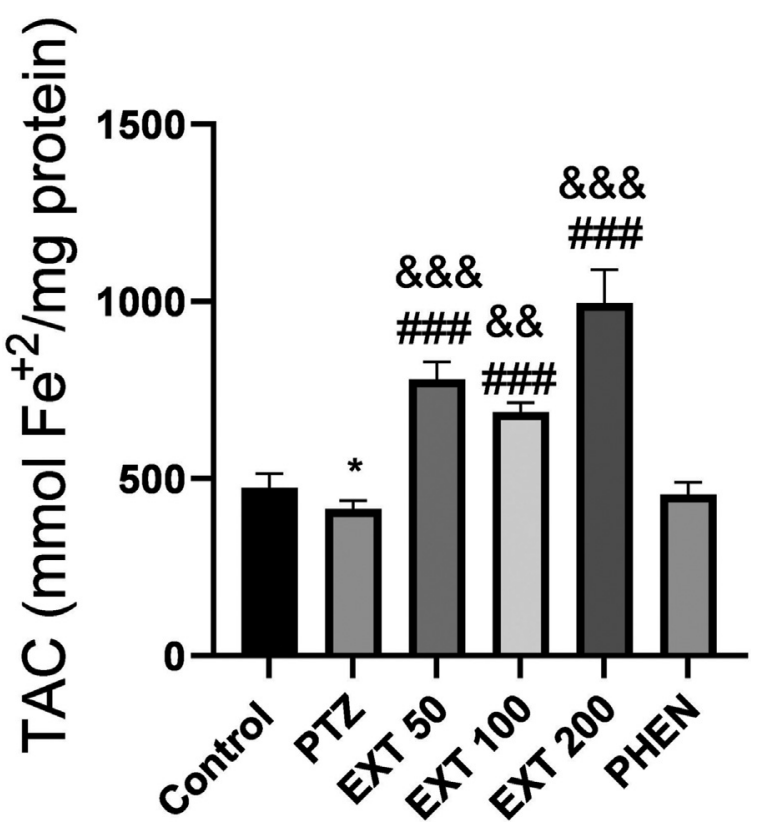

Fig. 2 Serum antioxidant capacity (micro $\mathrm{mol} \mathrm{Fe}^{+2} / \mathrm{mg}$ protein) in the experimental groups. Data are presented as mean \pm standard error from 10 mice and were analyzed using one-way analysis of variance followed by Tukey's post-hoc test. ${ }^{*} p<0.05$ compared with the control group, \#\#\#p<0.001 compared with the PTZ group, and $\& \& p<0.01$ and $\& \& \& p<0.001$ compared with the PHEN group. EXT, Anchusa italica Retz. hydro-alcoholic extract; PHEN, phenobarbital; PTZ, pentylenetetrazole; TAC, total antioxidant capacity.

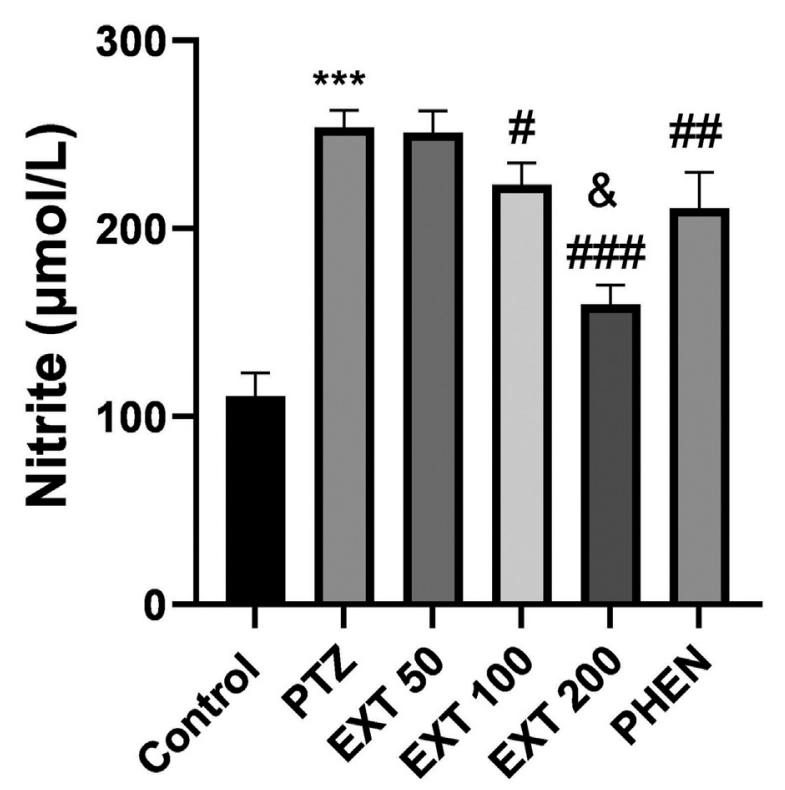

Fig. 4 Serum nitrite levels (micro $\mathrm{mol} / \mathrm{L}$ ) in the experimental groups. Data are presented as mean \pm standard error from 10 mice and were analyzed using one-way analysis of variance followed by Tukey's post-hoc test.

${ }^{* * *} p<0.001$ compared with the control group, $\# p<0.05$, \#\#p $<0.01$, and $\# \#$ \# $<0.001$ compared with the PTZ group, and \&p $<0.05$ compared with the PHEN group. EXT, Anchusa italica Retz. hydro-alcoholic extract; PHEN, phenobarbital; PTZ, pentylenetetrazole.

\section{Serum Nitrite Level}

Results showed that nitrite level in serum samples in the PTZ groups is significantly higher than in the control group $(p=0.0002 ;$-Fig. 4). We found that A. italica extract at doses of $100(p=0.035)$ and $200 \mathrm{mg} / \mathrm{kg}(p=0.0008)$ as well as phenobarbital $(p=0.003)$ significantly reduced the nitrite level in comparison with the PTZ group. In addition, finding showed that serum nitrite level in group treated with extract at dose of $200 \mathrm{mg} / \mathrm{kg}$ was significantly lower than group receiving phenobarbital ( $p=0.0251)$.

\section{Prefrontal Cortex TAC}

As - Fig. 5 presents, the TAC in the prefrontal cortex in the PTZ group is significantly lower than in the control group $(p=0.0004)$. Results showed that $A$. italica extract at doses of 50,100 , and $200 \mathrm{mg} / \mathrm{kg}$ significantly increased the TAC in the prefrontal cortex in comparison with the PTZ group $(p=0.0002)$. Moreover, results showed that prefrontal cortex TAC in groups treated with extract at doses of 50,100, and $200 \mathrm{mg} / \mathrm{kg}$ was significantly higher than group receiving phenobarbital $(p=0.0007)$.

\section{Prefrontal Cortex MDA Level}

Based on - Fig. 6, the MDA in the prefrontal cortex in the PTZ group is significantly higher than in the control group $(p=0.0005)$. We showed that A. italica extract at doses of 50,100 , and $200 \mathrm{mg} / \mathrm{kg}$ as well as phenobarbital significantly decreased the MDA in the prefrontal cortex in comparison with the PTZ group $(p=0.0003)$. In addition, finding showed 


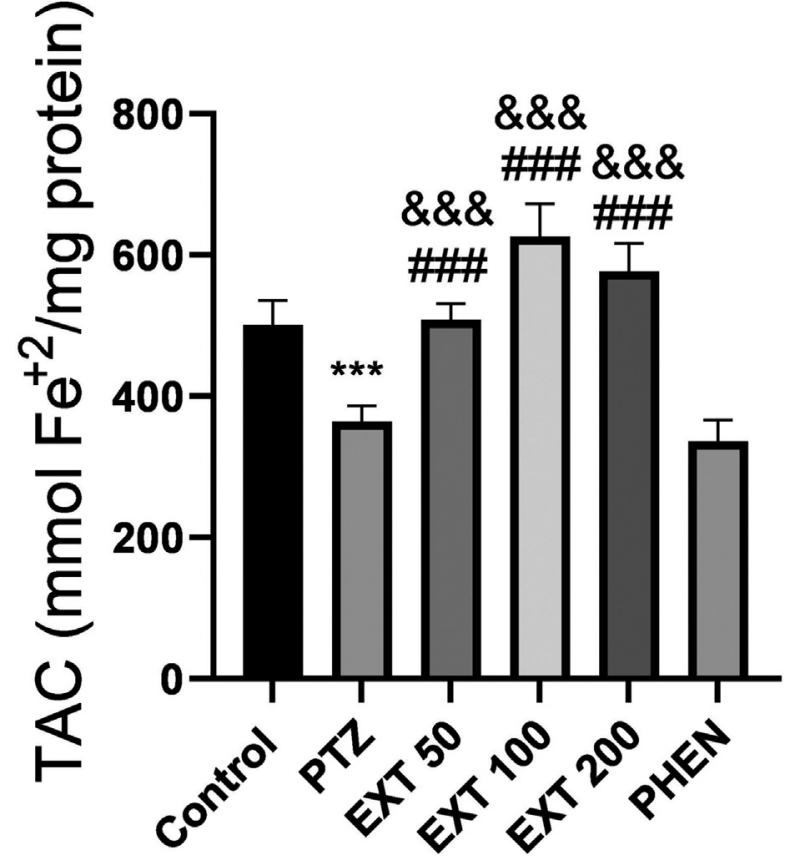

Fig. 5 Antioxidant capacity of prefrontal cortex (micro $\mathrm{mol} \mathrm{Fe}^{+2} / \mathrm{mg}$ protein) in the experimental groups. Data are presented as mean \pm standard error from 10 mice and were analyzed using one-way analysis of variance followed by Tukey's post-hoc test. ${ }^{* * *} p<0.001$ compared with the control group, $\# \# \# p<0.001$ compared with the PTZ group, and $\& \& \& p<0.001$ compared with the PHEN group. EXT, Anchusa italica Retz. hydro-alcoholic extract; PHEN, phenobarbital; PTZ, pentylenetetrazole; TAC, total antioxidant capacity.

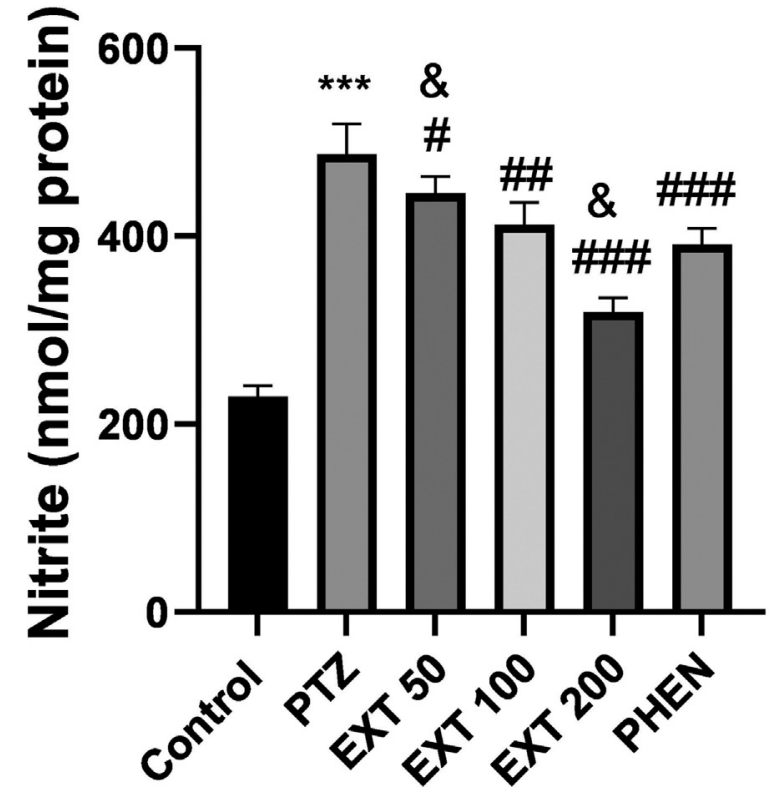

Fig. 7 Level of nitrite (nano $\mathrm{mol} / \mathrm{mg}$ protein) of prefrontal cortex in the experimental groups. Data are presented as mean \pm standard error from 10 mice and were analyzed using one-way analysis of variance followed by Tukey's post-hoc test. ${ }^{* * *} p<0.001$ compared with the control group, $\# p<0.05$, \#\#p $<0.01$, and \#\#\#p $<0.001$ compared with the PTZ group, and $\& p<0.05$ compared with the PHEN group. EXT, Anchusa italica Retz. hydro-alcoholic extract; PHEN, phenobarbital; PTZ, pentylenetetrazole.

that prefrontal cortex MDA level in group treated with extract at dose of $200 \mathrm{mg} / \mathrm{kg}$ was significantly lower than group receiving phenobarbital $(p=0.0274)$.

\section{Prefrontal Cortex Nitrite Level}

As - Fig. 7 shows, the level of nitrite in the prefrontal cortex of the PTZ group is significantly higher than in the control group ( $p=0.0004)$. Results showed that $A$. italica extract at doses of $50(p=0.0475), 100(p=0.0042)$, and $200 \mathrm{mg} / \mathrm{kg}$ $(p=0.0006)$ as well as phenobarbital $(p=0.0002)$ significantly reduced the nitrite level in the prefrontal cortex in comparison with the PTZ group. In addition, finding showed that prefrontal cortex nitrite level in group treated with extract at dose of $200 \mathrm{mg} / \mathrm{kg}$ was significantly lower than group receiving phenobarbital $(p=0.0482)$ while prefrontal cortex nitrite level in group treated with extract at dose of $50 \mathrm{mg} / \mathrm{kg}$ was significantly higher than group receiving phenobarbital $(p=0.0214)$.

\section{Discussion}

The findings of the present study showed that hydro-alcoholic extract of $A$. italica Retz. increased the seizure threshold in PTZ-induced seizure in mice. Results showed that hydroalcoholic extract of $A$. italica Retz. increased the antioxidant capacity as well as decreased the MDA and nitrite levels in the prefrontal cortex and serum samples (-Fig. 8).

Given the increasing rate of epilepsy worldwide and the low efficacy and various side effects of many synthetic drugs, 


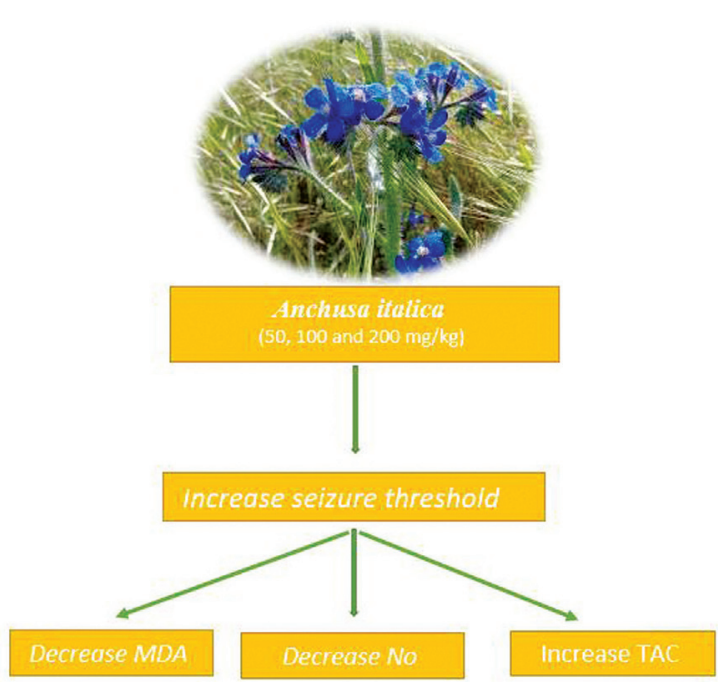

Fig. 8 Graphical abstract of the study.

finding new effective agents with low side effects seem to be necessary. ${ }^{24}$ Researchers are considering herbal medicines as potential therapies in treatment of diseases. ${ }^{25,26}$ Previous studies have demonstrated that the hydro-alcoholic extract of some medicinal plants like Viola tricolor significantly enhanced the seizure threshold. ${ }^{27}$ However, some herbal medicine has not been effective in epilepsy. ${ }^{28}$ Previous studies have demonstrated that $A$. italica extract possessed various pharmacological properties in animal model of diseases. $^{19,29}$ It has been determined that $A$. italica has antioxidant properties. ${ }^{30}$ Also, Torki et al (2018) revealed that $A$. italica through attenuation of oxidative stress state exerted neuroprotective effects in brain ischemia model in rats. ${ }^{19}$ The results of present study showed that $A$. italica Retz. extract, partially at least, through attenuation of oxidative stress state increased the seizure threshold. We observed that A. italica Retz. extract at dose of $200 \mathrm{mg} / \mathrm{kg}$ had high anticonvulsant efficacy compared with doses of 50 and 100 $\mathrm{mg} / \mathrm{kg}$ in PTZ-induced seizure in mice.

The role of oxidative stress in the pathophysiology of seizure has been determined in several studies. ${ }^{3,31}$ In this regard, it has been demonstrated that biomarkers of oxidative stress in patients with epilepsy are significantly higher than healthy subjects. ${ }^{32}$ Animal studies indicated that the induction of seizures by PTZ increased production of free radicals and led to oxidative damage to cells. ${ }^{33}$ Imbalance in oxidative/antioxidative systems may play a role in oxidative damage to neurons following seizure attacks. ${ }^{31}$ In the current study, hydro-alcoholic extract of $A$. italica Retz. displayed acceptable antioxidant activity in inhibition of 2,2-diphenyl1-picrylhydrazyl radicals. Therefore, this ability appears to be related to the antioxidant property of phenolic compounds present in A. italica Retz. extract. In this study, we found that hydro-alcoholic extract of $A$. italica Retz. contains high amounts of phenolic contents. The anticonvulsant effects of A. italica Retz. extract seem to be because of the presence of these compounds. Baradaran et al (2013) revealed that antioxidant activities of medicinal plants are due to secondary metabolites such as polyphenols. ${ }^{34}$

Prefrontal cortex is a part of the brain that is involved in the pathophysiology of seizures. ${ }^{35}$ In the present study, the antioxidant capacity of prefrontal cortex and serum samples in the PTZ group was lower than the control group. Besides, MDA levels in the prefrontal cortex and serum samples in the PTZ group were significantly higher than in the control group. In line with previous studies, we found that decrease in antioxidant capacity as well as increase in lipid peroxidation are associated with seizures. ${ }^{12}$ Our results showed that A. italica Retz. extract significantly increased the antioxidant capacity in serum and prefrontal cortex samples. Furthermore, A. italica extract significantly decreased the MDA levels in serum and prefrontal cortex samples. In general, it can be concluded that $A$. italica Retz. extract possessed antioxidant effects in PTZ model of seizure in mice.

Previous studies indicated that NO has an excitatory role in the pathogenesis of seizures. ${ }^{36}$ In this regard, it has been shown that inhibition of NO synthase led to anticonvulsant effects in different known models of seizure and attenuated seizure development. ${ }^{37}$ Moreover, it has also been reported that the increase in NO production led to mitochondrial dysfunction of neuronal cells leading to oxidative stress state and finally increased the incidence of seizures. ${ }^{38}$ In this study, nitrite levels in the serum and prefrontal cortex samples increased in the PTZ groups. We showed that A. italica Retz. extract significantly decreased nitrite levels in the serum and prefrontal cortex samples.

Overall, our finding demonstrated that A. italica Retz. extract, partially at least, via reducing nitrite and MDA levels as well as increasing antioxidant capacity in the prefrontal cortex possessed anticonvulsant effects in PTZ-induced seizure in mice.

\section{Conclusion}

According to the present study results, administration of the hydro-alcoholic extract of $A$. italica Retz. increased the seizure threshold in PTZ-induced seizure in mice. We found that anticonvulsant effects of hydro-alcoholic extract of A. italica Retz., partially at least, mediated through its antioxidant properties.

\section{Conflict of Interest}

None declared.

Acknowledgment

Authors are thankful to Mrs. Elham Bijad for her contribution to this work.

\section{References}

1 Gelfuso EA, Liberato JL, Cunha AO, et al. Parawixin2, a novel nonselective GABA uptake inhibitor from Parawixia bistriata spider venom, inhibits pentylenetetrazole-induced chemical kindling in rats. Neurosci Lett 2013;543:12-16

2 Ettore B. The epidemiology of epilepsy. Neuroepidemiology 2020; 54(02):185-191 
3 Haj-Mirzaian A, Ramezanzadeh K, Tafazolimoghadam A, et al. Protective effect of minocycline on LPS-induced mitochondrial dysfunction and decreased seizure threshold through nitric oxide pathway. Eur J Pharmacol 2019;858:172446

4 Potruch A, Khoury ST, Ilan Y. The role of chronobiology in drugresistance epilepsy: the potential use of a variability and chronotherapy-based individualized platform for improving the response to anti-seizure drugs. Seizure 2020;80:201-211

5 Patocka J, Wu Q Nepovimova E, Kuca K. Phenytoin - an antiseizure drug: overview of its chemistry, pharmacology and toxicology. Food Chem Toxicol 2020;142:111393

6 Hölscher C. Nitric oxide, the enigmatic neuronal messenger: its role in synaptic plasticity. Trends Neurosci 1997;20(07):298-303

7 Hassanipour M, Amini-Khoei H, Shafaroodi H, et al. Atorvastatin attenuates the antinociceptive tolerance of morphine via nitric oxide dependent pathway in male mice. Brain Res Bull 2016; 125:173-180

8 Kovács R, Rabanus A, Otáhal J, et al. Endogenous nitric oxide is a key promoting factor for initiation of seizure-like events in hippocampal and entorhinal cortex slices. J Neurosci 2009;29 (26):8565-8577

9 Watanabe M, Miyai A, Danjo S, Nakamura Y, Itoh K. The threshold of pentylenetetrazole-induced convulsive seizures, but not that of nonconvulsive seizures, is controlled by the nitric oxide levels in murine brains. Exp Neurol 2013;247:645-652

10 Liu A-H, Chu M, Wang Y-P. Up-regulation of Trem2 inhibits hippocampal neuronal apoptosis and alleviates oxidative stress in epilepsy via the PI3K/Akt pathway in mice. Neurosci Bull 2019; 35(03):471-485

11 Menon B, Ramalingam K, Kumar RV. Oxidative stress in patients with epilepsy is independent of antiepileptic drugs. Seizure 2012; 21(10):780-784

12 Asgharzade S, Rabiei Z, Rabiei S, Bijad E, Rafieian-Kopaei M. Therapeutic effects of oleuropein in improving seizure, oxidative stress and cognitive disorder in pentylenetetrazole kindling model of epilepsy in mice. Iran J Pharm Res 2020;19(01):98-110

13 Abdel-Salam OM, Sleem AA, Sayed MAM, Youness ER, Shaffie N. Capsaicin exerts anti-convulsant and neuroprotective effects in pentylenetetrazole-induced seizures. Neurochem Res 2020; 45:1045-1061

14 Kiasalari Z, Khalili M, Heidari H, Azizi Y. Anti-convulsant effect of alcoholic Hyoscyamus niger L seed extract on PTZ model of kindling in male mice. Majallah-i Ulum-i Pizishki-i Razi 2011; 18(85):27-33

15 Kiasalari Z, Khalili M, Heidari H. Investigation of anti-convulsant effect of alcoholic Ferula Assa Foetida gum extract PTZ-induced kindling model in mice. Daneshvar 2011;18(90):25-32

16 Alimohammadi B, Ajhdari H. Investigation of anti-convulsant effect of alcoholic Ferula Scrophularia striata extract PTZ-induced kindling model in mice. Edrak 2014;34:18-25

17 Al-Snafi A. The pharmacology of Anchusa italica and Anchusa strigosa-a review. Int J Pharm Pharm Sci 2014;6(04):7-10

18 Wang S, Zhao Y, Song J, et al. Total flavonoids from Anchusa italica Retz. improve cardiac function and attenuate cardiac remodeling post myocardial infarction in mice. J Ethnopharmacol 2020;257:112887

19 Torki A, et al. Anchusa italica extract: phytochemical and neuroprotective evaluation on global cerebral ischemia and reperfusion. Braz J Pharm Sci 2018;54(01):e17251

20 Amini-Khoei H, Rahimi-Balaei M, Amiri S, et al. Morphine modulates the effects of histamine $\mathrm{H} 1$ and $\mathrm{H} 3$ receptors on seizure susceptibility in pentylenetetrazole-induced seizure model of mice. Eur J Pharmacol 2015;769:43-47

21 Benzie IF, Strain JJ. Ferric reducing/antioxidant power assay: direct measure of total antioxidant activity of biological fluids and modified version for simultaneous measurement of total antioxidant power and ascorbic acid concentration. Methods Enzymol 1999;299:15-27

22 Kuloglu M, Atmaca M, Tezcan E, Ustundag B, Bulut S. Antioxidant enzyme and malondialdehyde levels in patients with panic disorder. Neuropsychobiology 2002;46(04):186-189

23 Lorigooini Z, Salimi N, Soltani A, Amini-Khoei H. Implication of NMDA-NO pathway in the antidepressant-like effect of ellagic acid in male mice. Neuropeptides 2019;76:101928

24 Steinlein OK, Mulley JC, Propping P, et al. A missense mutation in the neuronal nicotinic acetylcholine receptor $\alpha 4$ subunit is associated with autosomal dominant nocturnal frontal lobe epilepsy. Nat Genet 1995;11(02):201-203

25 González-Trujano ME, Urbina-Trejo E, Santos-Valencia F, Villasana-Salazar B, Carmona-Aparicio L, Martínez-Vargas D. Pharmacological and toxicological effects of Ruta chalepensis L. on experimentally induced seizures and electroencephalographic spectral power in mice. J Ethnopharmacol 2021;271:113866

26 Mombeini T, Asadpour Behzadi B, Ejtemaei R, Tahmasbi F, Kamalinejad M, Dehpour AR. Anticonvulsant effect of Alcea aucheri on pentylenetetrazole and maximal electroshock seizures in mice. Basic Clin Neurosci 2020;11(03):369-377

27 Baradaran Rahimi V, Askari VR, Hosseini M, Yousefsani BS, Sadeghnia HR. Anticonvulsant Activity of Viola tricolor against seizures induced by pentylenetetrazol and maximal electroshock in mice. Iran J Med Sci 2019;44(03):220-226

28 Aghdash , Simin N. Herbal medicine in the treatment of epilepsy. Curr Drug Targets 2021;22(03):356-367

29 Liu Y, et al. Chemical constituents of Anchusa italica Retz. and their protective effects on cardiomyocytes injured by hypoxia/ reoxygenation. Phytochem Lett 2020;38:155-160

30 Merlani M, et al. Antioxidant activity of caffeic acid derived polymer from Anchusa italica. Bull Georg Natl Acad Sci 2017;11 (02):123-127

31 Gupta YK, Veerendra Kumar MH, Srivastava AK. Effect of Centella asiatica on pentylenetetrazole-induced kindling, cognition and oxidative stress in rats. Pharmacol Biochem Behav 2003;74(03): 579-585

32 Sudha K, Rao AV, Rao A. Oxidative stress and antioxidants in epilepsy. Clin Chim Acta 2001;303(1-2):19-24

33 Zhao RR, Xu XC, Xu F, et al. Metformin protects against seizures, learning and memory impairments and oxidative damage induced by pentylenetetrazole-induced kindling in mice. Biochem Biophys Res Commun 2014;448(04):414-417

34 Bardakci H, Cevik D, Barak TH, Gozet T, Kan Y, Kirmizibekmez H. Secondary metabolites, phytochemical characterization and antioxidant activities of different extracts of Sideritis congesta $\mathrm{PH}$ Davis. Hub Mor Biochem Syst Ecol 2020;92:104120

35 Zubareva OE, Kovalenko AA, Kalemenev SV, Schwarz AP, Karyakin VB, Zaitsev AV. Alterations in mRNA expression of glutamate receptor subunits and excitatory amino acid transporters following pilocarpine-induced seizures in rats. Neurosci Lett 2018; 686:94-100

36 Gooshe M, Tabaeizadeh M, Aleyasin AR, et al. Levosimendan exerts anticonvulsant properties against PTZ-induced seizures in mice through activation of nNOS/NO pathway: role for $\mathrm{K}_{\mathrm{ATP}}$ channel. Life Sci 2017;168:38-46

37 Rehni AK, Singh TG, Kalra R, Singh N. Pharmacological inhibition of inducible nitric oxide synthase attenuates the development of seizures in mice. Nitric Oxide 2009;21(02):120-125

38 Gupta RC, Dettbarn WD. Prevention of kainic acid seizuresinduced changes in levels of nitric oxide and high-energy phosphates by 7-nitroindazole in rat brain regions. Brain Res 2003;981 $(1-2): 184-192$ 